\title{
THE FUTURE OF FLEXIBLE WORK ARRANGEMENTS IN A POST COVID-19 UNIVERSE
}

\author{
Jessica Bril, New York Institute of Technology, Old Westbury, New York, U.S.A. \\ Joshua E. Bienstock, New York Institute of Technology, Old Westbury, New York, U.S.A. \\ Anne L. Brown, New York Institute of Technology, Old Westbury, New York, U.S.A. \\ Stacey Baez, New York Institute of Technology, Old Westbury, New York, U.S.A. \\ Vincent Petraro, New York Institute of Technology, Old Westbury, New York, U.S.A. \\ Eleanor Schwartz, New York Institute of Technology, Old Westbury, New York, U.S.A. \\ Ute Broedje, New York Institute of Technology, Old Westbury, New York, U.S.A. \\ Cristina Seaman, New York Institute of Technology, Old Westbury, New York, U.S.A. \\ John LaPerla, New York Institute of Technology, Old Westbury, New York, U.S.A.
}

\author{
dx.doi.org/10.18374/RBR-20-2.4
}

\begin{abstract}
As the international business world has embraced a $24 / 7$ model to meet the demands of a global economy, the American worker struggles to balance the demands of home and work. Complicating matters, COVID-19 forced businesses around the world to reassess and readjust; for a time, many businesses were forced to shut down completely or try to operate by having their employees work from home. In New York State, non-essential workers were directed to stay home and were not permitted to work at their offices for nearly three months. (N.Y.S. Office of the Governor, 2020; Higgins-Dunn \& Kim, 2020). Technology has made some of this new reality less painful, yet employees nevertheless find working from home difficult and disruptive. Much of the stress is driven by the seemingly relentless demands of home and work colliding. Further, new complaints regarding Zoom meeting computer monitor fatigue have risen. On the brighter side, employees also report satisfaction that they no longer endure mentally and physically draining commutes. Despite these new challenges, the underlying fact remains that in the past few decades, the business world has increasingly embraced flexible work arrangements. The onslaught of COVID-19 hastened the uptick in the use of telecommuting and other flexible work arrangements. The true extent of the range and breadth (and permanency) of the growth of flexible work arrangements remains to be seen. This paper proposes a quantitative study to assess the future of flexible work arrangements in the small business world in the New York Metropolitan area. Two hundred and fifty (250) human resource managers will be surveyed to determine which flexible work arrangements will be favored and which will be rejected as impracticable in a small business environment.
\end{abstract}

Keywords: Flexible work arrangements, COVID-19, remote work, telecommuting, job sharing 